Gut, 1973, 14, 875-879

\title{
Lymphoblastic response to autologous colon epithelial cells in ulcerative colitis in vitro
}

\author{
P. S. HUNT AND S. TROTTER \\ From the Department of Surgery, Monash University, and the Gastroenterology Unit, \\ Prince Henry's Hospital, Melbourne, Australia
}

SUMMARY The blastic transformation in vitro of peripheral blood lymphocytes was measured by the 72-hour uptake of tritiated thymidine ( ${ }^{8} \mathrm{H}-6$-thymidine) in 23 patients with mucosal ulcerative colitis, three patients with acute Crohn's colitis with rectal involvement, and seven normal subjects. The 23 patients with ulcerative colitis were subdivided into three groups, graded according to severity into seven with acute, severe, nine with active, chronic, and seven with quiescent disease.

In the control cultures of lymphocytes without any added potential stimulant the uptake of ${ }^{3} \mathrm{H}-6$-thymidine in the clinical subgroup of seven patients with acute, severe ulcerative colitis was significantly greater than in seven normal subjects $(P<0.01)$. This contrasted with a reduced uptake of ${ }^{3} \mathrm{H}-6$-thymidine by lymphocytes from seven patients with acute severe colitis when compared with seven normal subjects after stimulation with phytohaemagglutinin-P (PHA-P) (P<0.01).

In further duplicate cultures of lymphocytes specifically stimulated by an equal number of viable autologous rectal epithelial cells, the uptake of ${ }^{3} \mathrm{H}$-6-thymidine was significantly greater in seven patients with acute severe colitis when compared with seven normal subjects $(P<0.01)$. The results in three patients with acute Crohn's colitis with rectal involvement showed no such evidence of lymphocyte sensitivity to autologous rectal epithelial cells and their uptake of ${ }^{3} \mathrm{H}-6$-thymidine lay within the normal range.

Evidence that the degree of lymphoblastic transformation was related to the clinical severity of ulcerative colitis was provided by the results obtained in the unstimulated and epithelial cell stimulant cultures. The uptake of ${ }^{3} \mathrm{H}-6$-thymidine was directly related to the clinical severity of ulcerative colitis in the three subgroups studied.

In addition, four of the seven patients with acute severe colitis were studied later in clinical remission. They were then found to have a significantly reduced uptake of ${ }^{3} \mathrm{H}-6$-thymidine in response to autologous rectal epithelial cells $(P<0.01)$.

In the normal cellular immune response blastic transformation of thymically directed lymphocytes is an important component of the process of recognition of certain antigens by the host. This transformation leads to the production of a group of effector cells which mediate a specific response against that antigen (Roitt, Greaves, Torrigiani, Brostoff, and Playfair, 1969). Lymphocytes from patients with ulcerative colitis have been found to damage autologous colon epithelial cells in culture (Shorter, Huizenga, Spencer, Aas, and Guy, 1972; Watson, Quigley, and Bolt, 1966). Should

Received for publication 14 August 1973. this lymphocytotoxicity represent an abnormal effector cell response in these patients, then colon epithelial cells would also be recognized by autologous lymphocytes by an increased rate of blastic transformation.

In this study the degree of abnormal autoimmune responsiveness is measured by the ability of viable rectal epithelial cells to stimulate blastic transformation in autologous lymphocytes in patients with ulcerative colitis, Crohn's colitis with rectal involvement, and in normal subjects. Transformation is measured by the 72-hour uptake of tritiated thymidine by peripheral blood lymphocytes (Ling, 1968). 


\section{Patients and Methods}

Twenty-three patients with mucosal ulcerative colitis were studied. These patients were subdivided on clinical grounds into seven inpatients with acute severe ulcerative colitis, nine patients with chronic active colitis, and seven patients with colitis in remission. The severity of ulcerative colitis was clinically assessed by sigmoidoscopic appearance and clinical state. All patients with ulcerative colitis had the clinical, radiological, and histological characteristics of acute non-specific mucosal ulcerative colitis (Morson, 1969). Three patients with acute Crohn's colitis with rectal involvement were also studied. The three patients with active Crohn's colitis had active rectal involvement, granulomata were shown histologically and were clinically characteristic of the disease. The age range of these patients was 19 to 62 years. A group of seven age- and sex-matched subjects with histologically and clinically normal colons were studied synchronously where possible as normal controls.

Fifteen $\mathrm{ml}$ blood samples were obtained by venepuncture in $1 \mathrm{ml}$ of $5 \%$ EDTA. Lymphocytes were separated from the sample of peripheral blood by a density gradient method. Two $\mathrm{ml}$ lots of blood were then mixed with $6 \mathrm{ml}$ of sterile normal saline in six 5in. $\times \frac{5}{8}$ in. siliconized tubes. A layering solution of Ficoll (Pharmacia), Conray 280 (May and Baker), and sterile distilled water was then infused through a polythene tube to lie below the blood-saline mixture. The tubes were then centrifuged at 1000 rpm for 20 minutes. After centrifugation the lymphocytes appeared as a fine band separated from red cells and polymorphs. The yield of live lymphocytes was consistently more than $80 \%$ of available cells with less than $5 \%$ red cell and polymorph contamination. Duplicate cultures of $1 \times 10^{6}$ lymphocytes were set up in five tubes each containing $1 \mathrm{ml}$ of medium 199 , with $20 \%$ foetal calf serum. The first tube contained unstimulated lymphocytes for measurement of spontaneous transformation in $2 \mathrm{ml}$ of culture medium alone. The second, third, and fourth tubes contained respectively $0.01 \mathrm{ml}, 0.002 \mathrm{ml}$, and $0.001 \mathrm{ml}$ of phytohaemagglutinin (PHA-P Bacto-Difco) per ml of culture medium. Maximal dose response is obtained with $0.01 \mathrm{ml}$ PHA-P/ml (Mackinney, 1964). The final two tubes were brought to $2 \mathrm{ml}$, with $1 \mathrm{ml}$ of $1 \times 10^{6}$ live colonic epithelial cells in a suspension of medium 199 with $20 \%$ foetal calf serum. The latter were separated from rectal biopsies by mincing, teasing, and scraping, and passage through layers of gauze. All cells were checked for viability by exclusion of $0.1 \%$ Trypan blue, and confirmed to be colonic epithelial cells by staining and microscopy. All culture tubes contained penicillin $(100 \mathrm{u} / \mathrm{ml})$, streptomycin $(100 \mathrm{u} / \mathrm{ml})$, neomycin $(100 \mathrm{u} / \mathrm{ml})$, and polymyxin $(200 \mathrm{u} / \mathrm{ml})$.

The cultures were incubated for 56 hours at $37^{\circ} \mathrm{C}$ in a humidified atmosphere of $5 \% \mathrm{CO}_{2}$ and then labelled for 16 hours with $2.5 \mu \mathrm{Ci}$ of tritiated thymidine $\left({ }^{3} \mathrm{H}-6\right.$-thymidine, $5000 \mathrm{Ci} / \mathrm{mM}$ New England Nuclear). Cultures were then stopped with cold phosphate-buffered saline, and precipitated with $5 \%$ trichloracetic acid. Weak acidinsoluble DNA was then dissolved by heating in a water bath to $90^{\circ} \mathrm{C}$ for 20 minutes. Then a $0.5 \mathrm{ml}$ sample was added to $10 \mathrm{ml}$ of Brays scintillation fluid. A Packard Tricarb scintillation counter was used to measure the uptake of ${ }^{3} \mathrm{H}-6$-thymidine. The counts were corrected for background.

Statistics were analysed by Wilcoxon's sum of ranks test.

\section{Results}

UNSTIMULATED LYMPHOBLASTIC RESPONSE The uptake of ${ }^{3} \mathrm{H}-6$-thymidine as a measure of blastic transformation of lymphocytes without added potential stimulant are shown in figure 1 . Spontaneous uptake of ${ }^{3} \mathrm{H}-6$-thymidine is seen to occur in the lymphocytes from normal subjects $(810 \pm 150 \text { counts per minute }(\mathrm{cpm}))^{1}$. This uptake

${ }^{1} A$ ll values mean $t$ standard deviation

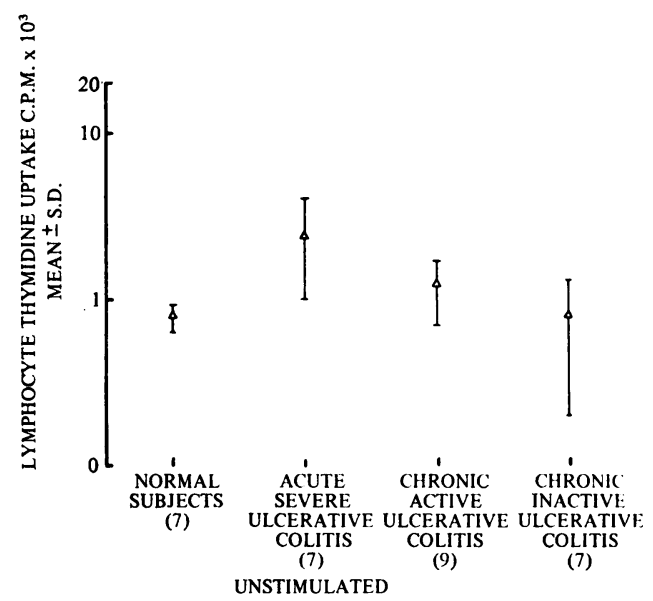

Fig 1 As a measure of lymphoblastic transformation in vitro the mean $(\triangle) \pm S D$ (vertical bars) of the uptake of ${ }^{3} \mathrm{H}$-6-thymidine $\left(\mathrm{cpm} \times 10^{3}\right)($ vertical semilog scale) is shown in 23 patients with ulcerative colitis and seven normal subjects. The uptake of ${ }^{3} \mathrm{H}$-6-thymidine is significantly less in normal sutjects and in those with chronic inactive colitis when compared with those patients with acute severe disease $(\mathrm{P}<0.01)$. 
is significantly less than found in the peripheral blood lymphocytes of seven patients with acute severe ulcerative colitis $(2550 \pm 1000 \mathrm{cpm})(\mathrm{P}<0.01)$. Also seen in fig 1 is a fall off in blastic transformation with decreasing severity of disease. The uptake of ${ }^{3} \mathrm{H}-6$-thymidine in nine patients with chronic active colitis was $1150 \pm 400 \mathrm{cpm}$ and in seven patients with chronic inactive colitis $750 \pm 600 \mathrm{cpm}$. The reduction in uptake between acute severe disease and chronic inactive colitis was significant $(\mathrm{P}<0.01)$. The uptake ${ }^{3} \mathrm{H}-6$-thymidine in three patients with active Crohn's (granulomatous) colitis was within the normal range at $970 \pm 60 \mathrm{cpm}$.

\section{NON-SPECIFIC LYMPHOBLASTIC RESPONSE}

TO PHA-P

The uptake of ${ }^{3} \mathrm{H}-6$-thymidine in response to varying concentration of PHA-P by the lymphocytes from seven normal subjects and seven patients with acute severe ulcerative colitis is shown in figure 2 . The significantly greater unstimulated uptake of ${ }^{8} \mathbf{H}-6$ thymidine by lymphocytes from patients with acute severe colitis is shown. This contrasts with the reversal to a lower uptake in acute ulcerative colitis after PHA stimulation of lymphocytes (fig 2).

All concentrations of PHA-P produced significantly less stimulation of lymphocytes in acute severe colitis than in normal subjects $(P<0.01)$. The uptake of ${ }^{3} \mathrm{H}-6$-thymidine in seven patients with

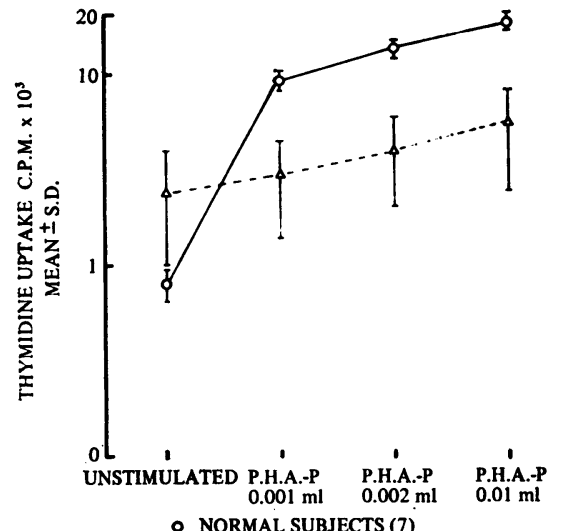

$\triangle$ ACUTE SEVERE ULCERATIVE COLITIS (7)

Fig 2 The mean $\pm S D$ (vertical bars) of uptake of ${ }^{8} \mathrm{H}$-6-thymidine in vitro by lymphocytes in seven patients with acute severe ulcerative colitis and seven normal subjects in response to the varying concentrations of PHA-P shown. In this study the non-specific lymphoblastic responsiveness is significantly less in acute severe colitis when compared with normal subjects at all concentrations of PHA-P $(\mathrm{P}<0.01)$. acute severe colitis to $0.001 \mathrm{ml}$ of PHA was $3050 \pm$ $1500 \mathrm{cpm}$, to $0.002 \mathrm{ml}, 4000 \pm 2000 \mathrm{cpm}$, and to $0.01 \mathrm{ml}, 5600 \pm 3000 \mathrm{cpm}$. In seven normal subjects the uptake in cpm to $0.001 \mathrm{ml}$ of PHA was $9600 \pm$ 750 , to $0.002 \mathrm{ml} 14300 \pm 1000$, and to $0.01 \mathrm{ml} 19700$ \pm 1400 .

\section{SPECIFIC LYMPHOBLASTIC RESPONSE TO AUTOLOGOUS RECTAL EPITHELIAL CELLS}

The results of specific uptake of ${ }^{3} \mathrm{H}$-6-thymidine by lymphocytes as a measure of their antigen recognition of autologous rectal epithelial cells is shown in figure 3. The uptake of ${ }^{3} \mathrm{H}-6$-thymidine

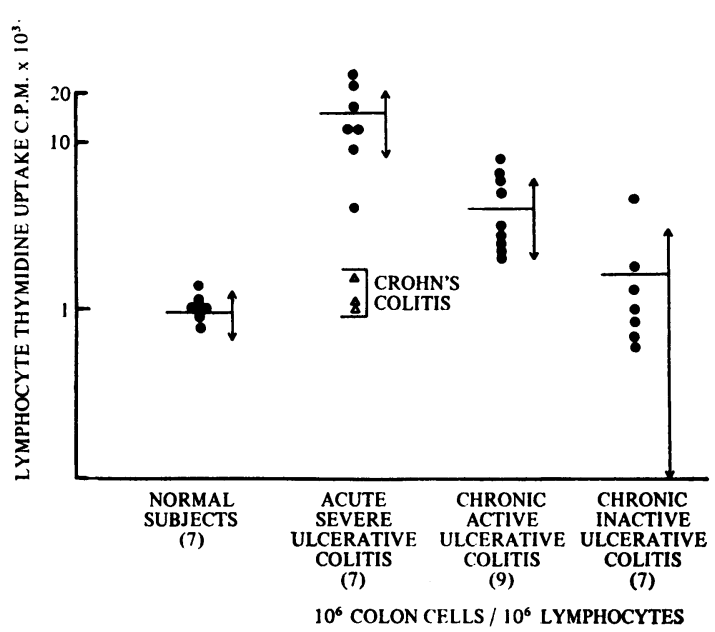

Fig 3 The lymphoblastic response after stimulation with large intestinal epithelial cells is shown as the mean $\pm S D$ of specific uptake of ${ }^{3} \mathrm{H}$-6-thymidine by lymphocytes in 23 patients with ulcerative colitis, three with acute Crohn's colitis with rectal involvement, and seven normal subjects. The uptake of ${ }^{3} \mathrm{H}$-6-thymidine is significantly less in normal subjects, Crohn's colitis, and those with chronic inactive ulcerative colitis when compared with that in patients with acute severe ulcerative colitis $(\mathrm{P}<0.01)$.

in lymphocytes from seven patients with acute severe ulcerative colitis was $14900 \pm 7000 \mathrm{cpm}$. This uptake was significantly greater than found in seven normal patients at $950 \pm 350 \mathrm{cpm}(\mathrm{P}<0.01)$. Figure 3 also shows a decreasing uptake in those with less severe disease. The uptake in nine patients with chronic active colitis was $4250 \pm 2200 \mathrm{cpm}$ and in seven patients with chronic inactive colitis it was $1600 \pm 1500 \mathrm{cpm}$. The uptake in acute disease was significantly greater than found in those patients with 
chronic inactive colitis $(P<0.01)$. Four patients were also studied later during remission of acute severe colitis. The uptake during the active phase of their disease was $14950 \pm 950 \mathrm{cpm}$ and significantly reduced later when in remission at $3200 \pm 1250$ cpm $(P<0.01)$.

Again shown in fig 3 the uptake of ${ }^{3} \mathrm{H}-6$-thymidine after stimulus with autologous rectal epithelial cells in three patients with active Crohn's colitis and rectal involvement was within the normal range.

\section{Discussion}

A proportion of human peripheral blood lymphocytes undergo blastic transformation when stimulated in vitro by non-specific mitogens such as PHA (Ling, 1968). The degree of responsiveness is a nonspecific measure of the functional integrity of the ' $T$ ' lymphocyte as a potential mediator of a cellular immune response (Ling, 1968; Oppenheim, 1968; Janossy and Greaves, 1968). Lymphocytes also respond in vitro by blastic transformation antigens to which the host is specifically sensitized (Ling, 1968). Such sensitization can also be demonstrated in vivo by a delayed hypersensitivity skin response to local injection of the antigen. Whereas the degree of skin reaction is difficult to measure, the lymphoblastic response in vitro (Ling, 1968) provides a quantitative assay of cellular immune sensitivity (Roitt et al, 1969; Valentine, 1971).

Both the delayed hypersensitivity skin response and lymphoblastic transformation in vitro have previously been studied in patients with colonic inflammatory disease (Kirsner, 1970). In contrast to normal subjects, patients with ulcerative colitis have been shown to have a delayed hypersensitivity skin reaction to autologous leucocytes (Watson, Styler, and Bolt, 1965) and E. coli pretreated colonic antigen but not to colonic antigen alone (Fink and Mais, 1968). These and other similar studies are difficult to interpret, revealing disease-associated phenomena which are hard to incorporate into an immunological hypothesis about the cause of ulcerative colitis. Because adequate control studies are difficult to set up in the study of human disease, one cannot imply from such studies that demonstrated effects prove that the cause of the disease is immunological (Kronman, 1971; Bloom, 1971).

The part of our study concerned with nonspecific lymphoblastic responsiveness reveals similar interpretive difficulties. Although the techniques of measuring lymphoblastic transformation in vitro give a range of results which can be correlated with disease severity (fig 1), the lack of immune specificity for PHA-induced transformation itself prevents further interpretation (Valentine, 1971). Factors which may alter non-specific lymphoblastic responsiveness such as immunosuppression or infection within a patient with ulcerative colitis are difficult to control.

The varying arithmetical methods of presenting uptakes of tritiated thymidine also make comparison between studies difficult. Most studies relate mitogen-induced transformation to spontaneous transformation of unstimulated lymphocytes. We have expressed results as crude counts per minute (figs 1 and 2). Patients with acute severe ulcerative colitis have a significantly higher spontaneous uptake of tritiated thymidine than is found in normal controls. The degree of transformation falls off with decreasing severity of disease (fig 1). It is of interest that this finding in acute severe ulcerative colitis is similar to that found in recipients with impending kidney graft rejection (Häyry, Lindström,Virolainen, Pasternak, and Lindfors, 1972) suggesting that colonic mucosa in these patients is being rejected in a similar manner by the host.

The lymphoblastic response to varying concentrations of PHA-P is seen to be significantly less than in normal controls in figure 2. This depression may, however, be an artifact because the relatively pure extraction of small lymphocytes by the density gradient method tends to exclude larger lymphoblastic forms undergoing transformation. Therefore because of the method the real uptake of tritiated thymidine by ' $T$ ' lymphocytes may be artificially reduced. Using different methods of lymphocyte separation a number of workers have shown normal PHA-induced lymphoblastic transformation in patients with active ulcerative colitis. (Hinz, Perlmann, and Hammarstrom, 1937; Parent, Barrett, and Wilson, 1971; Aas, Huizenga, Newcomer, and Shorter, 1972).

Crohn's colitis and ulcerative colitis have distinctly different clinical patterns in their characteristic forms. The failure to separate the disease in immunological terms has provided grounds for criticism of theories suggesting that ulcerative colitis is an autoimmune disease (Kronman, 1971). Attempts have been made to separate these colonic inflammatory diseases on grounds of different lymphoblastic responsiveness. Both Parent and his colleagues (1971) and Asquith and co-workers (1972) have shown depressed responsiveness in Crohn's disease but others have shown normal lymphoblastic transformation (Aas et al, 1972). The position is further confused by the findings of Aas and his colleagues (1972) that the spontaneous uptake of unstimulated lymphocytes is increased in active Crohn's colitis and normal in ulcerative colitis, the opposite of the findings in our study. Sachar, 
Taub, Brown, Present, Konelitz, and Janowitz, (1972) have concluded in a recent study that an intrinsic defect in lymphocyte responsiveness is a common, though not a constant or specific, finding in patients with both Crohn's disease and ulcerative colitis.

Lymphoblastic response to a specific antigen to some extent obviates the need for exhaustive controls as it represents an immunological reaction establishing host cellular immune sensitivity to that antigen (Valentine, 1971). In other studies antigenic stimulants have included extracts of foetal colon, diseased large bowel, normal colon, germ-free rat faeces, and strains of $E$. coli. While one group of investigators (Stefani and Fink, 1967) have reported a decreased response to various antigens, others have shown normal responses in patients with active ulcerative colitis when compared with normal subjects (Hinz et al, 1967; Parent et al, 1971). In our study, using viable autologous rectal epithelial cells as a stimulant, a significantly greater response was found in acute severe ulcerative colitis when compared with findings in normal subjects (fig 3). Disease specificity for this responsiveness is suggested by the lack of significant transformation in three patients with classical Crohn's colitis with rectal involvement. Lymphoblastic transformation decreased to within the normal range for those patients with quiescent ulcerative colitis and was therefore also related to the clinical severity of the disease process.

We should like to thank Professor J. McK. Watts Dr J. Hansky, Dr M. Korman, Dr H. Hillman, and Dr G. Schmidt of the Gastroenterology Unit, Prince Henry's Hospital, for the opportunity to study their patients. We should also like to thank Mrs Barlow for efficiently typing this paper.

\section{References}

Aas, J., Huizenga, K. A., Newcomer, A. D., and Shorter, R. G. (1972). Inflammatory bowel disease: lymphocytic responses to nonspecific stimulation in vitro. Scand. J. Gastroent., 7, 299-303. Asquith, P., Kraft, S. C., and Rothberg, R. M. (1972). Lympho- cyte responses to nonspecific mitogens in inflammatory bowel disease. (Abstr.) Gastroenterology, 62, 718.

Bloom, B. R. (1971). Methods for study of mediators. In In vitro Methods in Cell-Mediated Immunity, edited by B. R. Bloom and P. R. Glade, pp. 3-93. Academic Press, New York and London.

Fink, S., and Mais, R. F. (1968). Cell mediated immune reaction to colon altered by bacteria. Gut, 9, 629-632.

Hăyry, P., Lindström, B. L., Virolainen, M., Pasternack, A., and Lindfors, O. (1972). Immunological diagnosis of rejection in dogs with renal allografts. Surgery, 71, 494-506.

Hinz, C. F., Jr., Perlmann, P., and Hammarstrom, S. (1967). Reactivity in vitro of lymphocytes from patients with ulcerative colitis. J. Lab. clin. Med., 70, 752-759.

Janossy, G., and Greaves, M. F. (1971). Lymphocyte activation. I. Response of $\mathrm{T}$ and $\mathrm{B}$ lymphocytes to phytomitogens. Clin. Exp. Immunol., 9, 483-498.

Kirsner, J. B. (1970). Ulcerative colitis (1970). Scand. J. Gastroent., Suppl., 6, 63-91.

Kronman, B. S. (1971). Ulcerative colitis, auto-immune epiphenomena and colonic cancer. Cancer (Philad.), 28, 82-88.

Ling, N. R. (1968). Lymphocyte Stimulation. Wiley, New York. North Holland Publ. Co., Amsterdam.

Mackinney, A. A., Jr. (1964). Dose response curve of phytohaemagglutinin in tissue culture of normal human leucocytes. Nature (Lond.), 204, 1002-1003.

Morson, B. C. (1969). Pathology. In Ulcerative Colitis, by J. C. Goligher, F. T. de Dombal, J. M. Watts, and S. Watkinson, pp. 5-31. Bailliere Tindall and Cassell, London.

Oppenheim, J. J. (1968). Relationship of in vitro lymphocyte transformation to delayed hypersensitivity in guinea pigs and man. Fed. Proc. 27, 21-28.

Parent, K., Barrett, J., and Wilson, I. D. (1971). Investigations of the pathogenic mechanisms in regional enteritis with in vitro lymphocyte cultures. Gastroenterology, 61, 431-439.

Roitt, I. M., Greaves, M. F., Torrigiani, G., Brostoff, J., and Playfair, J. H. L. (1969). The cellular basis of immunological responses. Lancet, 2, 367-371.

Sachar, D. B., Taub, R. N., Brown, S. M., Present, D. H., Korelitz, B. I., and Janowitz, H. D. (1972). Lymphocvte responsiveness in inflammatory bowel disease. (Abstr.) Gastroenterology, 62, 804.

Shorter, R. G., Huizenga, K. A., Spencer, R. J., Aas, J., and Guy, S. K. (1971). Inflammatory bowel disease, cytophilic antibody and the cytotoxicity of lymphocytes for colonic cells in vitro. Aner. J. dig. Dis., 16, 673-678.

Stefani, S., and Fink, S. (1967). Effect of $E$. coli antigens, tuberculin and phytohaemagglutinin upon ulcerative colitis lymphocytes. Gut, 8, 249-252.

Valentine, F. (1971). Contribution to symposium on methods for study of mediators. In In vitro Methods in Cell-Mediated Immunity, edited by B. R. Bloom and P. R. Glade, pp. 66-74. Academic Press, New York and London.

Watson, D. W., Quigley, A., and Bolt, R. J. (1966). Effects of lymphocytes from patients with ulcerative colitis on human adult colon epithelial cells. Gastroenterology, 51, 985-993.

Watson, D. W., Styler, H. J., and Bolt, R. J. (1965). The autologous leucocyte skin test in patients with ulcerative colitis. Gastroenterology, 49, 649-655. 